\title{
Debt Constraints and the Labor Wedge
}

\author{
By Patrick Kehoe, Virgiliu Midrigan, and Elena Pastorino*
}

This paper is motivated by the strong correlation between changes in household debt and in aggregate employment across regions of the United States during the Great Recession. As Mian and Sufi (2014) have documented, regions of the United States where the decrease in household debt was most pronounced were also regions where the decline in employment was most severe.

This paper documents that the drop in employment in the regions that have experienced the largest decrease in household debt is mostly accounted for by changes in the labor wedge (deviations from a static consumption-leisure choice) as opposed to changes in real wages. We then argue that such a pattern is consistent with a Bewley-Aiyagari model in which agents face uninsurable idiosyncratic risks and can borrow up to a fraction of the value of their homes. As long as consumption and housing enter the utility function in a non-separable form, a tightening of debt constraints acts like an implicit tax on labor. Whether this implicit tax is sufficiently large to generate a drop in employment depends on the strength of the wealth effects on labor supply. Our main finding is that if wealth effects are sufficiently weak, then the model implies a reduction in employment following a tightening of debt constraints even in the absence of price and wage rigidities or constraints on monetary policy.

\footnotetext{
* Kehoe: Department of Economics, University of Minnesota, 4-101 Hanson Hall, 1925 Fourth Street South, Minneapolis, MN 55455 (e-mail: patrickjameskehoe@ gmail.com); Midrigan: Department of Economics, New York University, 19 W. 4th Street, 6FL, New York, NY 10012 (e-mail: vm50@nyu.edu); Pastorino: Department of Economics, University of Minnesota, 4-101 Hanson Hall, 1925 Fourth Street South, Minneapolis, MN 55455 (e-mail: epastori@umn.edu). We thank Ali Shourideh for useful comments, and Sonia Gilbukh, Eugenia Gonzalez Aguado, and Sergio Salgado Ibanez for excellent research assistance. We are grateful to Erik Hurst for sharing his programs and data with us.

${ }^{\dagger}$ Go to http://dx.doi.org/10.1257/aer.p20161088 to visit the article page for additional materials and author disclosure statement $(\mathrm{s})$.
}

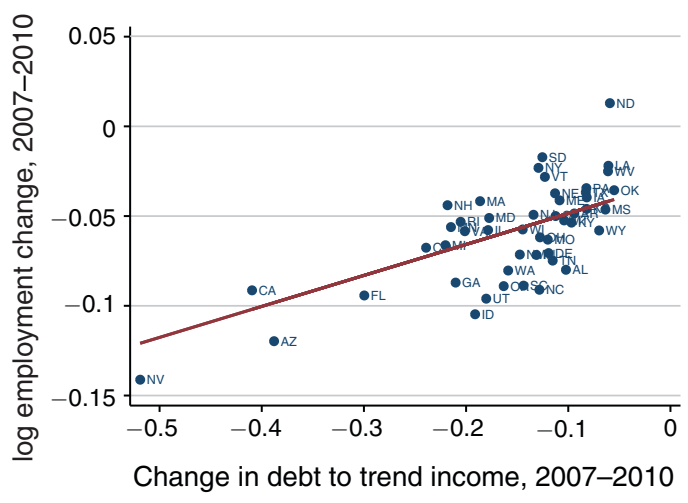

Figure 1. Employment and Household Debt

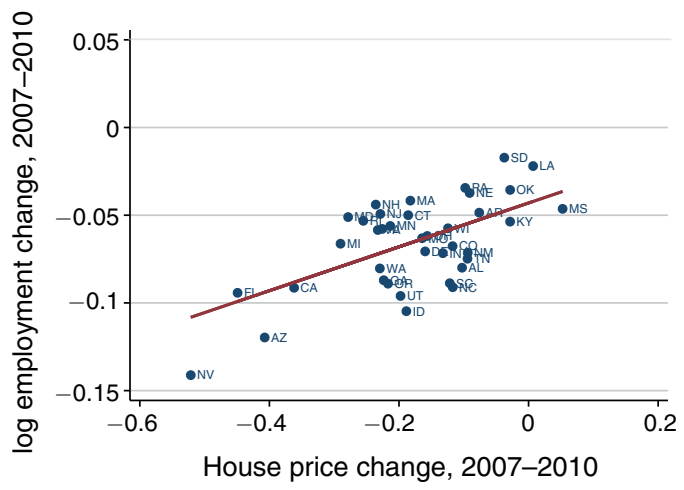

Figure 2. Employment and House Prices

\section{Evidence}

Figures 1 and 2 show the cross-sectional relationship between changes in employment, household debt, and house prices between 2007 and 2010. The positive association between these variables is quite evident in the figures.

We next argue that distortions in the consumption-leisure choice partly account for these patterns. To do so, consider a consumer who maximizes $U(c, n)=u(c)-v(n)$ subject to a budget constraint, where after-tax real 


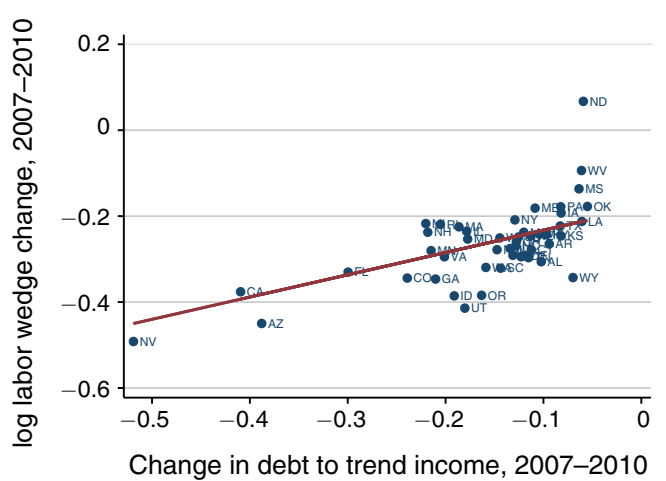

Figure 3. Wedge and Debt (Standard)

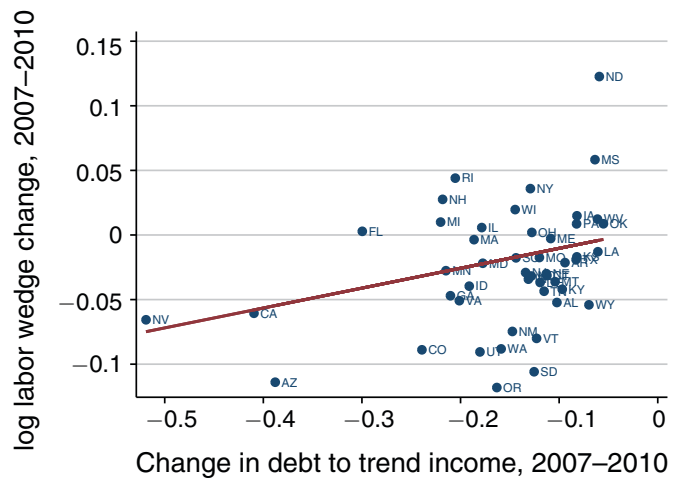

Figure 4. Wedge And Debt $(G H H)$

labor income is $(1-\tau) w n$. Here, $w$ is the real wage, $\tau$ is a tax on labor, and $c$ and $n$ are consumption and employment. We can recover the labor wedge $1-\tau$ from the first-order condition $1-\tau=-U_{n} /\left(w U_{c}\right)$. In Figures 3 and 4, we graph the labor wedge in a cross section of US states against changes in debt for standard preferences, $\quad U(c, n)=\frac{c^{1-\sigma}}{1-\sigma}-\frac{n^{1+1 / \nu}}{1+1 / \nu}, \quad$ and the preferences in Greenwood, Hercowitz, and Huffman (1988)—hereafer, GHH—preferences $U(c, n)=\frac{1}{1-\sigma}\left(c-\frac{n^{1+1 / \nu}}{1+1 / \nu}\right)^{1-\sigma}$. In Figures 5 and 6 , we graph the change in the labor wedge for both preferences against the change in employment.

To interpret these figures, manipulate the first-order condition for labor supply for $\mathrm{GHH}$

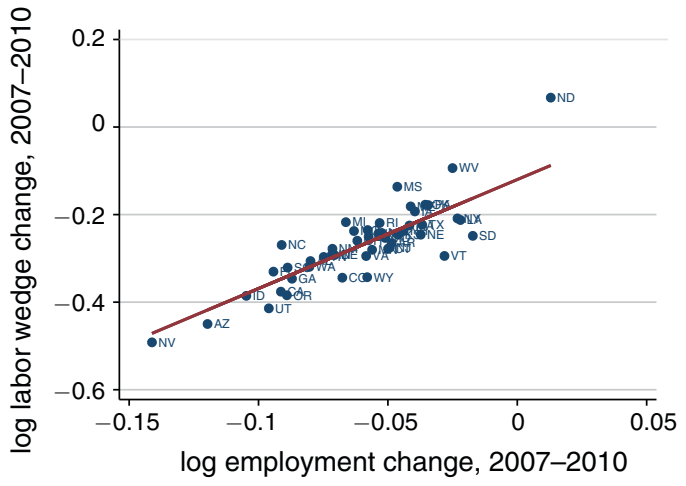

Figure 5. Wedge And Employment (Standard)

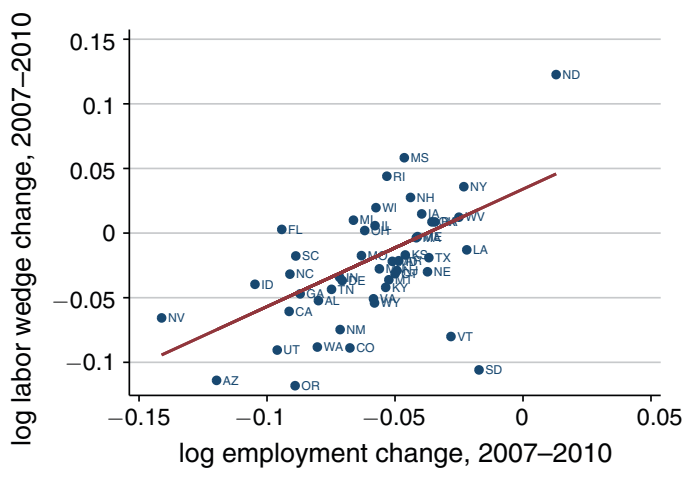

Figure 6. Wedge ANd EMPLOYMENT $(G H H)$

preferences to decompose the change in employment into the change in the labor wedge and in the real wage as

$$
\ln \left(\frac{n_{2010}}{n_{2007}}\right)=\nu \ln \left(\frac{1-\tau_{2010}}{1-\tau_{2007}}\right)+\nu \ln \left(\frac{w_{2010}}{w_{2007}}\right) .
$$

The decomposition for standard preferences is similar except that it has an additional term involving the change in consumption. (See online Appendix for details.) The slopes of the (weighted) regression lines in Figures 5 and 6 are 2.43 and 0.82 , respectively, both significant. Taken together, Figures 3 to 6 show that the employment decline was associated with a worsening of the labor wedge rather than just with a change in real wages and, possibly, consumption. 


\section{Model}

We consider a closed economy populated by a continuum of agents who face uninsurable idiosyncratic labor market risks. The model we study focuses on the role that borrowing constraints linking borrowing to house values have in shaping the dynamics of the labor wedge. (In related work, Guerrie and Lorenzoni 2015 study a model similar to ours with exogenous borrowing constraints.) We first describe the household's problem, the equilibrium, and then derive the optimal decision rules of the household.

\section{A. Household's Problem}

An agent's labor market income in a given period is $w_{t} z_{i t} n_{i t}$, where $w_{t}$ is the wage expressed in units of the consumption good, $z_{i t}$ is the agent's efficiency of labor, and $n_{i t}$ is the agent's labor supply; $i \in[0,1]$ indexes agents. The agent's problem is

$$
\max \sum_{t=0}^{\infty} \beta^{t} V\left(g\left(c_{i t}, h_{i t}\right), n_{i t}\right),
$$

subject to a budget constraint,

$$
\begin{aligned}
c_{i t}+ & q_{t}\left(h_{i t+1}-h_{i t}\right)+b_{i t+1} \\
& =w_{t} z_{i t} n_{i t}+\left(1+r_{t-1}\right) b_{i t},
\end{aligned}
$$

and a borrowing constraint,

$$
b_{i t+1} \geq-\theta q_{t} h_{i t+1},
$$

which specifies that the maximal loan, $-b_{i t+1}$, an agent can take in period $t$ is a fraction $\theta$ of the value of the house, $q_{t} h_{i t+1}$, that the agent has purchased in period $t$. We refer to $\theta$ as the maximal loan-to-value ratio. Here $c_{i t}$ is the agent's nondurable consumption and $h_{i t}$ is the flow of housing services consumed, assumed proportional to the housing stock, and $g(c, h)=\left(c^{\frac{\varepsilon-1}{\varepsilon}}+\eta^{\frac{1}{\varepsilon}} h^{\frac{\varepsilon-1}{\varepsilon}}\right)^{\frac{\varepsilon}{\varepsilon-1}}$, the composite consumption good, is an aggregator of consumption and housing services with an elasticity of substitution $\varepsilon$. Agents take as given the time paths of house prices, $q_{t}$, and interest rates, $r_{t}$. Here agent $i$ supplies $z_{i t} n_{i t}$ efficiency units of labor in period $t$, where $z_{i t}$ is idiosyncratic across agents and evolves over time according to

$$
\log z_{i t+1}=\rho_{z} \log z_{i t}+\sigma_{z} \epsilon_{i t+1},
$$

with $\epsilon_{i t+1}$ is i.i.d. standard normal, so that agent $i$ supplies $z_{i t} n_{i t}$ efficiency units of labor in period $t$.

\section{B. Equilibrium}

The consumption good is produced by perfectly competitive firms with a technology that is linear in efficiency units of labor, $y_{t}=l_{t}$. Competition among firms implies that the real wage per efficiency units of labor is $w_{t}=1$. The housing stock is fixed at one so that $\int h_{i t+1} d i=1$. Market clearing in asset and the labor markets imply that $\int b_{i t+1}=0$ and $l_{t}=\int z_{i t} n_{i t} d i$. There is no aggregate uncertainty in this economy. Below we study the steady-state properties of the model as well as the perfect-foresight transition dynamics following a one-time unanticipated decline in the maximal loan-to-value ratio, $\theta$.

\section{Decision Rules}

We simplify the state variables in the analysis by assuming that agents can adjust their housing stock in period $t$ after the realization of their idiosyncratic efficiency, $z_{i t}$. Under this assumption, an agent's financial position is summarized by the net worth

$$
a_{i t}=b_{i t}+q_{t-1} h_{i t},
$$

and an agent's period $t$ state is $\left(a_{i t}, z_{i t}\right)$. The agent's problem in recursive form is

$$
\begin{aligned}
W_{t}\left(a_{i t}, z_{i t}\right) & =\max _{a_{i t+1}, c_{t}, h_{t}, n_{t}} V\left(c_{t}, h_{t}, n_{t}\right) \\
& +\beta \int_{z_{i t+1}} W_{t+1}\left(a_{i t+1}, z_{i t+1}\right) d F\left(z_{i t+1} \mid z_{i t}\right),
\end{aligned}
$$

subject to the budget constraint

$$
c_{i t}+u_{t} q_{t} h_{i t}+a_{i t+1}=w_{t} z_{i t} n_{i t}+\left(1+r_{t-1}\right) a_{i t},
$$

and the borrowing constraint

$$
q_{t-1} h_{i t} \leqslant a_{i t} /(1-\theta) .
$$

Here $u_{t}=\left(1+r_{t-1}\right) q_{t-1} / q_{t}-1$ is the user cost of housing: an increase in interest rates or 
Panel A. Consumption

Panel B. Housing
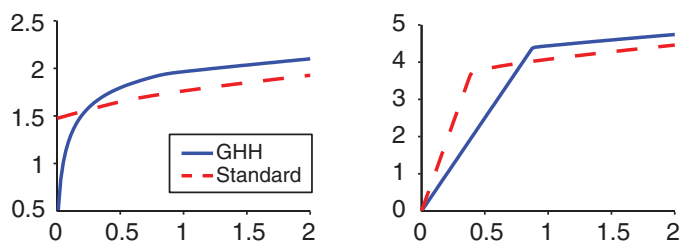

Panel C. Hours

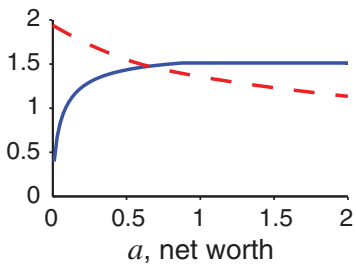

Figure 7. Decision Rules versus Net Worth

a house price depreciation makes houses relatively more costly to own. Note that allowing agents to adjust their housing stock after the realization of $z_{i t}$ means that housing is chosen in a static fashion, just as nondurable consumption, and the only dynamic choice is that of net worth, $a_{i t+1}$.

The housing choice can be written as

$$
\begin{aligned}
h_{i t} & =\min \left[\eta\left(u_{t} q_{t}\right)^{-\varepsilon} c_{i t}, \frac{a_{i t}}{(1-\theta) q_{t-1}}\right] \\
& =\eta\left[\left(u_{t}+\mu_{i t}\right) q_{t}\right]^{-\varepsilon} c_{i t},
\end{aligned}
$$

where $\mu_{i t}$ is the normalized multiplier on the borrowing constraint and is positive for households with sufficiently low net worth.

The labor supply choice equates the marginal rate of substitution between labor, $n_{i t}$, and the composite consumption good, $g_{t}$, to the real wage in composite consumption good units,

$$
-V_{n, i t} / V_{g, i t}=w_{t} z_{i t} / p_{i t},
$$

where $p_{i t}=\left\{1+\eta\left[\left(u_{t}+\mu_{i t}\right) q_{t}\right]^{1-\varepsilon}\right\}^{\frac{1}{1-\varepsilon}}$ is the (shadow) composite price of the consumptionhousing aggregator and varies across households. This equation highlights the key force we focus on later, namely, the negative effect of tighter borrowing constraints on labor supply: agents who are more borrowing constrained have higher normalized multipliers, $\mu_{i t}$, and thus supply less labor than they would, absent the borrowing constraint.

Figure 7 summarizes this discussion by illustrating an agent's consumption, housing, and employment choices for different values of net worth for standard preferences, $V(g, n)=\frac{g^{1-\sigma}}{1-\sigma}-\frac{n^{1+1 / \nu}}{1+1 / \nu}$, and GHH preferences, $V(g, n)=\frac{1}{1-\sigma}\left(g-\frac{n^{1+1 / \nu}}{1+1 / \nu}\right)^{1-\sigma}$. With GHH preferences, there are no wealth effects on labor supply, so the poorest agents, namely those with the lowest assets, are relatively more borrowing constrained and, hence, supply less labor. The GHH version of the model can therefore account, at least qualitatively, for the positive correlation between employment and household wealth (as proxied by changes in house prices) in Figure 2. Figure 7 also makes it clear that an increase in the amount of wealth inequality - a mean preserving spread in $a_{t}-$ would reduce labor supply in the economy without wealth effects on labor supply, by raising the proportion of agents who are borrowing constrained.

\section{Responses to a Tightening of Borrowing Constraints}

We illustrate the mechanism discussed above using a simple quantitative example. We first discuss the parameter values we have used and then the response to a one-time reduction in the maximal loan-to-value ratio, $\theta$.

\section{A. Calibration}

The period is one year. We set the persistence of labor productivity as $\rho_{z}=0.79$ and its volatility as $\sigma_{z}=0.34$, in line with the literature. We set the Frisch elasticity of labor supply, $\nu$, equal to 1 and assume $\varepsilon=1 / \sigma=1 / 2$. Clearly, the elasticity of substitution between consumption and housing $\varepsilon$ is critical for our results: reducing it amplifies the effect of borrowing constraints on employment, while raising it reduces this effect. Like earlier, we work with two types of preferences, standard and GHH. We set $\theta$ equal to 0.80 in the initial steady state and choose the parameter governing the importance of housing in preferences as $\eta=0.32$ as well as the discount factor as $\beta=0.88$, to ensure that the 
Panel A. Output, consumption

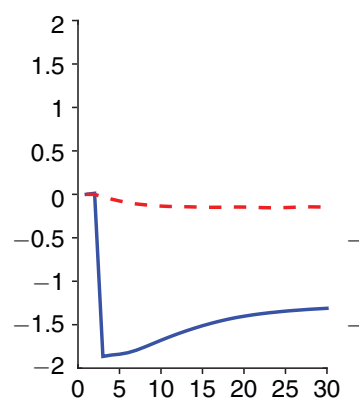

$$
\begin{array}{|l|}
\hline \text { - GHH } \\
\text { - - Standard }
\end{array}
$$

Figure 8. Transitions After a Credit Tightening

housing-to-income ratio in the model is equal to 2.2 and that the risk-free rate is equal to 2 percent, numbers in line with US evidence.

\section{B. Transition Dynamics}

Figure 8 shows how the economy evolves following a one-time unanticipated reduction in $\theta$ from 0.8 to 0.5 .

The less interesting case is that with standard preferences. Here employment increases following a tightening of the borrowing constraint because, quantitatively, the wealth effect on labor supply emanating from the large drop in wealth overwhelms the effect of the tightened borrowing constraint. Thus, there is a large increase in households' labor supply, especially the poorest ones, who are now even more constrained in their borrowing. Over time such households save in order to relax their borrowing constraints.

The case of interest is that with GHH preferences in which there are no such wealth effects. In this case, the tightened borrowing constraint leads to a reduction in the labor supply of the poor households. Here employment falls visibly after a credit tightening and never fully recovers. Output falls in both versions of the model, though much more in the economy with GHH preferences.

\section{Matching US Wealth Inequality}

As is well known, simple versions of the Bewley-Aiyagari models like ours are incapable
Panel A. Output, consumption

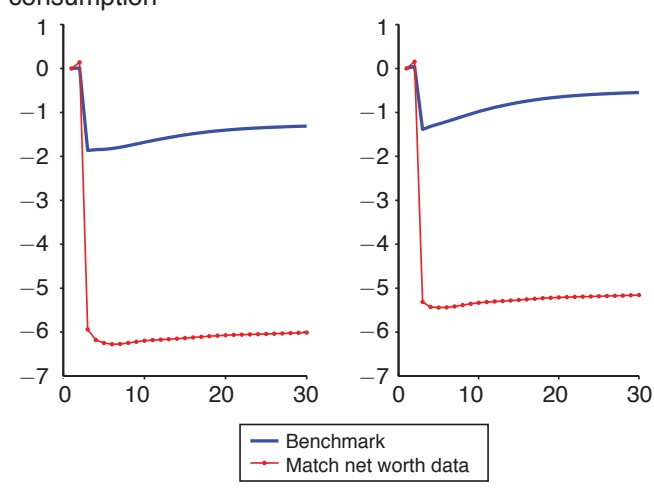

Figure 9. Transitions in Economy with LaRge Wealth INEQUALITY

of reproducing the large amount of wealth inequality observed in the data. For example, in our baseline model with GHH preferences, the ratio of debt to income is only equal to 0.65 , much lower than the 0.92 observed in the 2001 Survey of Consumer Finances (SCF) data. Similarly, the ratio of the wealth of households in the ninety-fifth percentile to that of the median household is equal to 15 in the data and only 7 in the model.

To address these discrepancies, we consider a greater wealth inequality version of the $\mathrm{GHH}$ model in which we allow agents to differ in their discount factors (we assume a three-point distribution) and choose the dispersion in discount factors to match moments of the net worth distribution in the United States. ${ }^{\mathbb{1}}$ This version is capable of replicating a much higher debt-to-income ratio (0.81) as well as a ninety-fifth to fiftieth wealth ratio of 14 , and thus is much closer to the data. In addition, a larger fraction of agents are constrained in this version of the model (39 percent compared to 13 percent in the benchmark model). Figure 9 displays the responses of aggregates to a tightening of borrowing constraints in the benchmark GHH model and in the greater wealth inequality version of that model. Clearly, the same tightening of borrowing constraints has a much larger impact on output and employment in the greater wealth inequality

\footnotetext{
${ }^{1}$ We used $\beta=\{0.36,0.87,0.96\}$ and $\omega=\{0.30,0.62,0.08\}$ for the fraction of agents of each type.
} 
version. This result occurs because a greater number of agents are borrowing constrained in this version.

\section{Conclusion}

We have shown that in a cross section of US states, reductions in household credit were associated with what a simple representative-agent model of labor supply would interpret as evidence of an increase in labor market distortions. A simple Bewley-Aiyagari model can be made consistent with such facts, even in the absence of price or wage rigidities or constraints on monetary policy, as long as housing and consumption enter in a non-separable fashion in the utility function. Whether such forces imply that a tightening of borrowing constraints is associated with a reduction in employment depends on the strength of wealth effects in the model. When wealth effects are large, as with standard preferences, a tightening of borrowing constraints implies an increase in aggregate employment. With GHH preferences, there are no such wealth effects and a tightening of borrowing constraints predicts a decline in employment.

\section{REFERENCES}

Greenwood, Jeremy, Zui Hercowitz, and Gregory W. Huffman. 1988. "Investment, Capacity Utilization, and the Real Business Cycle." American Economic Review 78 (3): 402-17.

Guerrieri, Veronica, and Guido Lorenzoni. 2015. "Credit Crises, Precautionary Savings, and the Liquidity Trap." Unpublished.

-Mian, Atif, and Amir Sufi. 2014. "What Explains the 2007-2009 Drop in Employment?" Econometrica 82 (6): 2197-2223. 
This article has been cited by:

1. Lini Zhang. 2018. Credit crunches, individual heterogeneity and the labor wedge. Journal of Macroeconomics 56, 65-88. [Crossref] 